\title{
Performance Improvement of Distribution Network Using Capacitors and Distributed Generation Units
}

\author{
G. Harisha ${ }^{1}$, Dr. A. Lakshmi Devi ${ }^{2}$ \\ M. Tech, Dept. of EEE, S.V. University College of Engineering ${ }^{1}$ \\ Professor, Dept of EEE, S.V. University College of Engineering ${ }^{2}$
}

\begin{abstract}
Capacitors and DGs are commonly used in distribution system for real or reactive power compensation so that it reduces the losses, increases the maximum flow through cables and in transformers, and also improves the system power factor and voltage profile. The Reduction of losses in distribution system is very essential to improve overall efficiency of power delivery. This can be achieved by placing capacitors and DGs at different locations in radial distribution system. By considering the above advantages, in this paper to improve voltage profile and to reduce losses to increase efficiency in radial distribution system, the location and sizing of capacitors and DGs are addressed using two main factors. They are loss sensitivity factor for location and particle swarm optimization algorithm for sizing is used. To show the effectiveness, obtained results are compared each other. The proposed method is programmed and tested in a IEEE 33 bus distribution system using MATLAB software. For load flow analysis of the distribution network, Newton-Raphson method is used.
\end{abstract}

Index Terms: Radial distribution system, loss sensitivity factor, PSO Algorithm, Capacitor placement, DG placement.

\section{INTRODUCTION}

The loss minimization in distribution system has assumed greater significance recently, since the trend towards distribution automation will require the most efficient operating scenario for economic viability variations. The power losses in distribution system correspond to about $70 \%$ of total losses in electric power systems. To overcome this problem capacitor and DG are installed in primary distribution network. There are many methods for DG and Capacitor placement for different purposes like improvement of voltage profile, reduction of losses, improvement of power factor, and reduction of total cost and net savings of distribution system. A distribution network operation can be improved by placement and sizing of capacitor and DG. The optimization problem namely placement and sizing of capacitor and DG should be formulated with the desired objective loss minimization methods. After that suitable techniques should be applied for location, type, size and control settings at different load levels of the capacitors and DGs should be installed [1-2]. In this paper, a new heuristic algorithm for solving the problem of capacitor and DG placement and sizing in distribution system is proposed. Loss sensitivity factor is used to determine the optimal placement and particle swarm optimization technique is used to determine the size of the capacitors and DGs. The proposed method is tested on 33-bus radial distribution system and the results obtained are effective and encouraging.

\section{1: Capacitor Placement:}

Historically, to improve the distribution networks, first initialize with the placement and appropriate size of capacitor selection. Because all the arrangements in electrical homes system are done to meet up the basic requirement of alternating power system, reactive power always comes in to picture. The demand of this reactive power is mainly originated from inductive load connected to the system. This reactive power should be properly compensated otherwise, the total power i.e. vector sum of active and reactive power, of the system becomes quite less. This ratio is alternatively known as electrical power factor. If the power factor of the system is poor, the ampere burden of the transmission, distribution network, transformers, alternators and the other equipments connected to the system, becomes high for required active power. And hence reactive power compensation becomes so important. This is commonly done by capacitor bank.

Here shunt capacitors are more commonly used in the power system of all voltage levels. There are some specific advantages of using shunt capacitors such as, reduces line current of the system, improves voltage level of the load, reduces system Losses, improves power factor of the source current, and also It reduces capital investment per mega watt of the Load. All the above mentioned benefits come from the fact, that the effect of capacitor reduces reactive current flowing through the whole system. Shunt capacitor draws almost fixed amount of leading current which is superimposed on the load current and consequently reduces reactive components of the load and hence improves the power factor of the system.

The proposed work in this case is as follows: Determining the place and size of capacitors in distorted distribution system is discussed and particle swarm optimization algorithm is used for optimization. The objective function is referred to reduce losses, improvement of voltage profile, optimize power and capacitor placement cost and net savings of the system. The methodology used for 
location of capacitors is loss sensitivity factor and for sizing of capacitors is particle swarm optimization algorithm is applied.

\subsection{DG Placement:}

It has been established that $70 \%$ of total losses occur in the distribution system due to its low $\mathrm{X} / \mathrm{R}$ ratio and low voltage operation. There are several techniques for minimizing the distribution losses such as feeder reconfiguration, reinforcement of the feeder, grading of conductor, construction of new substation, reactive power compensation, optimal placement of capacitor and DG etc. Because of increasing popularity of DG, it is utilized in this paper for minimizing losses. Studies show that upto $70 \%$ of the losses can be minimized by the proper placement DGs of optimal size at the right locations.

DG is a small generating unit based on the non-renewable or renewable energy connected to the distribution side of the power system with capacity ranging from a few kilowatts to upto several megawatts.

In a radial network due to line drop, voltage decreases with increasing distance from the substation. Placing DG can compensate this voltage drop and thus improve the power quality which inturn increase efficiency and performance of equipments connected to the system.

The objective of this work is to find out the location and sizes of the DG so as to minimize the net savings by minimizing the energy loss cost for a given period of time with single DG, double DGs, and 3DGs. The installation cost and unit energy generation cost of DG is also taken into account. The following assumptions are considered for DG placement.

1) The sizing and location of DG is considered at the peak load only

2) Maximum active power limit of DG for different test systems is assumed to be equal to the total active load of the system.

3) The lower and upper voltage thresholds for DG with the optimal size, location and power factor are set at 0.95 $1.05 \mathrm{pu}$.

Particle Swarm Optimization algorithm is used for finding the optimal places of DGs and the results are compared and discussed.

1.3. Review of previous methods used for improvement of distribution network:

DG allocation and sizing studies are relatively more efficient than capacitor placement and sizing.

S.Bouri in [4] presented an ant colony optimization approach for capacitor placement in distribution system under certain constraints. The voltage constraints were taken into account by specifying upper and lower limits of voltage variations at the nodes of distribution system.

Azim and Swarup in [5] presented a GA-based approach to determine the optimum location and sizing of capacitors for a distribution system. A genetic algorithm is used as optimization tool, which obtained optimal values and location of capacitors and minimized the objective function, which was the power loss in the distribution network under study.
Prakash and Sydulu in [1] presented a novel based approach that determines the optimal placement and sizing of capacitor in radial distribution system to improve voltage profile and reduce the active ppower loss of the system.

In this paper a new approach i.e., placement and sizing of capacitors and DGs are used to get better performance improvement in voltage profile and power losses of the system when compared to only capacitor placement . PSO Algorithm is used as optimization tool to get better optimization.

\section{PROBLEM FORMULATION}

\subsection{Capacitor}

The objective of the optimal capacitor placement and sizing problem in this study is to minimize the total annual cost function of capacitor placement and power loss, which is given by

$$
\mathrm{K}^{\mathrm{p}} \mathrm{P}_{\text {loss }}+\sum_{\mathrm{j}=1}^{\mathrm{J}} \mathrm{K}_{\mathrm{j}}^{\mathrm{c}} \mathrm{Q}_{\mathrm{j}}^{\mathrm{c}}
$$

Where $P_{\text {loss }}$ is the total power loss

$\mathrm{K}^{\mathrm{p}}$ Is the annual cost per unit of power loss $(\$ / \mathrm{KW})$,

$\mathrm{K}_{\mathrm{j}}^{\mathrm{c}}$ Is the capacitor annual cost (\$/KVAR),

$Q_{j}^{c}$ Is the shunt capacitor size placed at bus $j$ and $J$ is the number of candidate buses for capacitor placement.

The control variables are the shunt capacitors size $\left(Q^{c}\right)$ which are discrete variables. Table1 shows the available capacitor sizes and corresponding yearly cost for variable capacitor sizes [6].

The constraints that need to be satisfied are listed below,

a) Shunt capacitor limits

$$
\mathrm{Q}_{\max }^{\mathrm{c}} \leq \mathrm{Q}_{\text {total }}
$$

Where $Q_{\max }^{c}$ the largest capacitor size is allowed and $Q_{\text {total }}$ is the total reactive load

b) Bus bar voltage limits

$$
V_{\min }<V_{i}<V_{\max }
$$

In radial power systems

$V_{\min }=0.9$ and $V_{\max }=1.1$

c) Line flow limits

$$
\text { Flow }_{k}<\text { Flow }_{k}^{\max }
$$

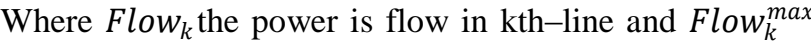
is the maximum allowable power flow.

\subsection{Distributed Generation:}

The objective of placement of DG in this study is to minimize the voltage profile and loss reduction of the distribution system, which is given by

a) Each bus voltage $\left(V_{i}\right)$ must be maintained around its nominal value $\left(V_{i \text { nom }}\right)$ within the permissible limits, specified as

$$
\left[\begin{array}{ll}
V_{i \min } & V_{i \max }
\end{array}\right]
$$

Where,

$V_{i \min }$ is the minimum permissible value of voltage at bus $\mathrm{i}$ $V_{i \max }$ is the maximum permissible voltage at bus $\mathrm{i}$

This can be mathematically described as,

$$
V_{i \min } \leq V_{i} \leq V_{i \max }
$$

b) The capacity of each DG $\left(P_{D G}\right)$ should be also varied around its nominal value. Hence each $P_{D G}$ must also be maintained within permissible limits, specified as $\left[P_{D G \min } P_{D G \text { max }}\right]$ Where, 
c) $P_{D G \min }$ is the minimum permissible value of each DG capacity.

d) $P_{D G \text { max }}$ is the maximum permissible value of each DG capacity.

e) This should be a mandatory requirement because e.g. if a DG capacity is less than the specified minimum value, then the type and cost of the corresponding DG should also be varied. The DG capacity limit is given as,

f) $P_{D G \min } \leq P_{D G} \leq P_{D G \max }$

\section{LOSS SENSITIVITY FACTOR}

Consider a distribution line connected between ' $\mathrm{p}$ ' and ' $\mathrm{q}$ ' buses, as shown in fig1.

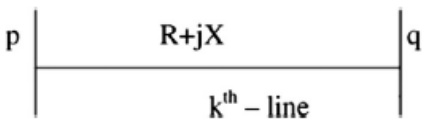

Fig1: A Distribution line between buses $\mathrm{p}$ and $\mathrm{q}$
The active power loss $P_{\text {loss }_{k}}$ in the kth line is given by

$$
P_{l o s s_{k}}=I_{p q}^{2} R_{p q}=\frac{S_{p q}^{2}}{V_{p}^{2}} R_{p q}=\frac{P_{p q}^{2}+Q_{p q}^{2}}{V_{p}^{2}} R_{p q}
$$

Now, the loss sensitivity factor is given by:

$$
\frac{\partial P_{\text {loss }} k}{\partial Q_{p q}}=\frac{2 Q_{p q}}{V_{p}^{2}} R_{p q}
$$

The loss sensitivity factors are calculated from base case load flow (i.e., without compensation) and the values are arranged in descending order for all the transmission lines of the given system. A vector that holds the respective "end buses" of the lines arranged in descending order of the values of the loss sensitivity factors is stored. The bus with inflowing power is the one considered for capacitor placement. The descending order of the loss sensitivity factors will decide the sequence in which the buses are to be considered for compensation [1].

\begin{tabular}{llllllll}
\hline \multicolumn{1}{c}{ Table 1 } & \multicolumn{7}{c}{ Yearly cost of fixed capacitors } \\
\hline Capacitor size (KVAR) & 150 & 300 & 450 & 600 & 750 & 900 & 1050 \\
Capacitor cost (\$/year) & 0.5 & 0.35 & 0.253 & 0.22 & 0.276 & 0.183 & 0.228 \\
Capacitor size (KVAR) & 1200 & 1350 & 1500 & 1650 & 1800 & 1950 & 2100 \\
Capacitor cost (\$/year) & 0.17 & 0.207 & 0.201 & 0.193 & 0.187 & 0.211 & 0.176 \\
Capacitor size (KVAR) & 2250 & 2400 & 2550 & 2700 & 2850 & 3000 & 3150 \\
Capacitor cost (\$/year) & 0.197 & 0.17 & 0.189 & 0.187 & 0.183 & 0.18 & 0.195 \\
Capacitor size (KVAR) & 3300 & 3450 & 3600 & 3750 & 3900 & 4050 & \\
Capacitor cost (\$/year) & 0.174 & 0.188 & 0.17 & 0.183 & 0.182 & 0.179 & \\
\hline
\end{tabular}

\section{THE PROPOSED ALGORITHM}

The steps for optimization using PSO algorithm is shown below.

Step1: The data to be fed as input are listed below.

i. Number of buses

ii. Load demand (active (watt) and reactive (VAR) power) at each bus.

iii. Bus voltage limits $\left(V_{\min }, V_{\max }\right)$.

iv. Transmission lines impedances (resistance and reactance).

v. Transmission lines capacity (maximum allowable power flow).

vi. Particle swarm optimization (PSO) parameters (number of particles, maximum number of iterations, acceleration constants $C_{1}$ and $C_{2}$ and initial inertial weight).

Step2: Perform the initial power flow (or load flow) analysis using Newton raphson algorithm without capacitor compensation to calculate the loss sensitivity factors and the values are arranged in descending order for all the lines of the given system. Then, determine the candidate buses requiring for capacitor placement.

Step3: Select the suitable range of capacitors from table1 such that

$$
Q_{i}^{c} \leq Q_{\max }^{c} \leq Q_{\text {total }}
$$

Step4: Randomly initialize the position of particles. Each position is a two-dimensional matrix. Thus, the position of the particles are represented by the following three dimensional-matrix

$$
X_{J \times R \times N N D}=\left[Q_{1}^{c}, \ldots, Q_{i}^{c}, \ldots, Q_{J}^{c}\right]
$$

Where $\mathrm{J}$ is the number of candidate buses for reactive compensation, NIND is the number of particles, $\mathrm{R}$ is the number of allowable capacitor sizes (e.g. if the available $Q^{c}$ sizes that satisfy equation (9) are $[150,300,450,600]$, then $\mathrm{R}=4$ and $Q_{i}^{c}$ is the reactive power installed at bus i. To select the capacitor size $Q_{i}^{c}$ to be placed at bus $i$, a combination of capacitor sizes is chosen fromTable1,

$$
Q_{i}^{c}=b_{1} S Z_{1}+b_{2} S Z_{2}+\cdots+\cdots+b_{R} S Z_{R}
$$

Where $b_{k} \in\{0,1\}$ and $S Z_{k}$ are the capacitor sizes.

Step5: Initialize the velocity of the particles.

Step6: Perform the power flow (or load flow) analysis using Newton raphson method for each particle to get the following

1) The active power $\operatorname{loss}\left(P_{\text {loss }}\right)$

2) The voltage at each bus $\left(V_{b u s}\right)$

3) Transmission line flows to determine the overloaded lines.

Step7: Calculate the total annual cost function for each particle

Step8: Calculate the fitness function (FF) for each particle.

$\mathbf{F F}=\left\{\cos t+\sum_{i=1}^{\text {Nload }}(\right.$ penalty factor $) \times\left(V_{i}-V_{\text {min }}\right)^{2}+$ $i=1 \mathrm{Nload}$ (penalty factor $) \times($ flowi - flowimax $) 2$

Where the penalty factor is assigned as follows for radial distribution systems 
penalty factor $=$

$\left(\begin{array}{cc}0 & \text { if constraints are not violated } \\ 500 \times \text { cost } \times \text { iteration } 2 & \text { if constraints are violated }\end{array}\right)$

Step9: Computer particles' fitness functions and update the personal (individual) best $\left(\right.$ Pbest $_{i}$ ) for each particle and the global best (gbest) through all the particles.

Step10: Update the particles' velocities according to the following equation

$$
\begin{gathered}
v_{i}^{t+1}=w^{(t)} v_{i}^{(t)}+c_{1} \times r_{1} \times\left(p \text { Best }_{i}^{(t)}-X_{i}^{(t)}\right)+ \\
c_{2} \times r_{2} \times\left(\text { gBest }^{(t)}-X_{i}^{(t)}\right) \quad \ldots \ldots \ldots(11)
\end{gathered}
$$

Where $X_{i}^{(t)}$ is the position vector of the ith particle in iteration number $\mathrm{t}$,

$v_{i}^{(t)}$ is its velocity vector,

$r_{1}$ and $r_{2}$ are two random numbers in the unit interval,

$c_{1}$ and $c_{2}$ are two acceleration constants giving different weights to the personal best position and the global best position, and $w^{(t)}$ is the inertial weight.

Step11: Update the particle positions for a binary discrete search space, Kennedy and Eberhart have adapted the PSO to search in binary spaces by applying a sigmoid transformation to the velocity component to squash the velocities into a range $[0,1]$ and then forcing the component values of the locations of particles to be 0's and 1 's. The equations for updating positions are given by $\operatorname{sigmoid}\left(\mathrm{v}_{\mathrm{i}}^{(\mathrm{t}+1)}\right)=\frac{1}{1+\mathrm{e}^{-\mathrm{v}_{\mathrm{i}}^{(\mathrm{t}+1)}}}$

$\mathrm{X}_{\mathrm{i}}^{(\mathrm{t}+1)}=\left\{\begin{array}{lr}1 & \text { if rand }<\operatorname{sigmoid}\left(\mathrm{v}_{\mathrm{i}}^{(\mathrm{t}+1)}\right) \\ 0 & \text { otherwise }\end{array}\right.$

Where rand is a random number between $[0,1]$.

Step12: Update the inertial weight according to the following equation

$\mathrm{w}^{(\mathrm{t})}=\mathrm{w}_{\text {max }}-\left(\frac{\mathrm{w}_{\max }-\mathrm{w}_{\min }}{\text { iterm }}\right) \times \mathrm{t}$

Where $w^{(t)}$ is the inertial weight in iteration $t$, $\mathrm{w}_{\max }$, and $\mathrm{w}_{\min }$ are the upper and lower limits of the inertial weight respectively, iterm is the maximum number of iterations and $\mathrm{t}$ is the iteration counter. The inertial weight balances global and local exploration and it decreases linearly from $\mathrm{w}_{\max }$ to $\mathrm{w}_{\min }$.

Step13: Return to step (6) until reaching the maximum number of iterations.

\begin{tabular}{|c|c|c|c|c|c|}
\hline \multicolumn{6}{|c|}{ Table 2: } \\
\hline $\mathrm{C}_{1}$ & $\mathrm{C}_{2}$ & $\mathrm{w}_{\max }$ & $\mathrm{w}_{\min }$ & Itermax & NIND \\
\hline 2 & 2 & 0.9 & 0.4 & 100 & 100 \\
\hline
\end{tabular}

\section{RESULTS}

The proposed method was tested on 33-bus radial distribution system and results have been obtained to evaluate its effectiveness by considering specifications as annual cost per unit of power lossesk $\mathrm{k}^{\mathrm{p}}$ is taken as 168 $\$ / \mathrm{KW}$. The voltage limits are taken as $V_{\min }=0.9$ and $\mathrm{V}_{\text {max }}=1.1$. The algorithm of this method is programmed in MATLAB R2011a environment. The results obtained in these methods are explained in the following sections.

\section{1: 33-Bus System}

The single line diagram is shown in figure2. The base values of the system are taken as $12.66 \mathrm{KV}$ and 100MVA. At this stage the distribution network does not contain any DG and capacitor. The network has relatively high losses i.e., 220.95, load bus voltages are not desirable and the annual cost function of the power losses is $\$ 37,250$. In addition high power passes through the first line of the network. Therefore, active and reactive power compensation is required to improve overall network status.

\section{1: 33-Bus System}

The single line diagram is shown in figure2. The base values of the system are taken as $12.66 \mathrm{KV}$ and 100MVA.

At this stage the distribution network does not contain any DG and capacitor. The network has relatively high losses i.e., 220.95, load bus voltages are not desirable and the annual cost function of the power losses is $\$ 37,250$. In addition high power passes through the first line of the network. Therefore, active and reactive power compensation is required to improve overall network status.

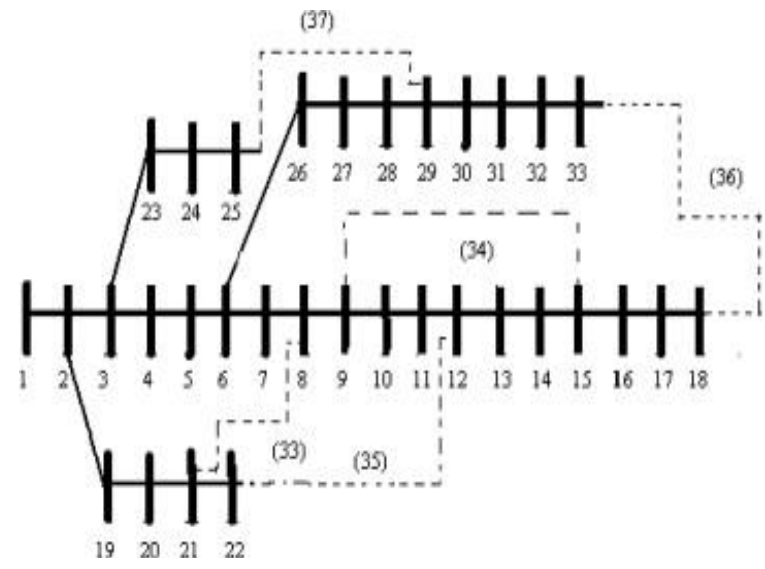

Fig2: 33-Bus Distribution System

The second and third steps are placement and sizing of capacitors and DGs in the network. The loss sensitivity factors are calculated for each transmission line from this initial load flow. The loss sensitivity values are listed in descending order are given in Table 3 along with the bus identification and normalized voltage magnitudes. The optimal location and sizing of capacitors and DGs are determined using PSO algorithm with the parameters indicated in Table 2.

The average, maximum and minimum active power losses and the standard deviation of the results of 15 independent runs are listed in Table4. Table5 shows the average, maximum and minimum total cost. Table6 shows the

\begin{tabular}{|c|c|c|c|}
\hline $\begin{array}{l}\text { Average } \\
(\mathrm{KW})\end{array}$ & $\begin{array}{l}\text { Minimum } \\
\text { (KW)best }\end{array}$ & $\begin{array}{l}\text { Maximum } \\
\text { (KW)(worst) }\end{array}$ & $\begin{array}{l}\text { Standard } \\
\text { Deviation }\end{array}$ \\
\hline 159.78 & 157.77 & 161.79 & 2.01 \\
\hline
\end{tabular}
average, maximum and minimum net saving.

Table5: statistics for the total cost for 33-bus radial system

\begin{tabular}{|l|l|l|l|}
\hline $\begin{array}{l}\text { Average } \\
(\$ / Y e a r)\end{array}$ & $\begin{array}{l}\text { Minimum } \\
(\$ / \text { Year }) \text { best }\end{array}$ & $\begin{array}{l}\text { Maximum }(\$ \\
\text { /Year)worst }\end{array}$ & $\begin{array}{l}\text { Standard } \\
\text { Deviation }\end{array}$ \\
\hline 26843 & 26800 & 26886 & 43 \\
\hline
\end{tabular}


INTERNATIONAL JOURNAL OF INNOVATIVE RESEARCH IN ELECTRICAL, ELECTRONICS, INSTRUMENTATION AND CONTROL ENGINEERING Vol. 3, Issue 12, December 2015

Table6: statistics for the net saving for the 33-bus radial system

\begin{tabular}{|l|l|l|l|}
\hline $\begin{array}{l}\text { Average } \\
(\mathrm{KW})\end{array}$ & $\begin{array}{l}\text { Minimum } \\
(\mathrm{KW})(\mathrm{best})\end{array}$ & $\begin{array}{l}\text { Maximum } \\
(\mathrm{KW})(\text { worst })\end{array}$ & $\begin{array}{l}\text { Standard } \\
\text { Deviation }\end{array}$ \\
\hline 10407 & 10364 & 10450 & 43 \\
\hline
\end{tabular}

The related graphs shows the comparison between the capacitor and DG used in proposed PSO method

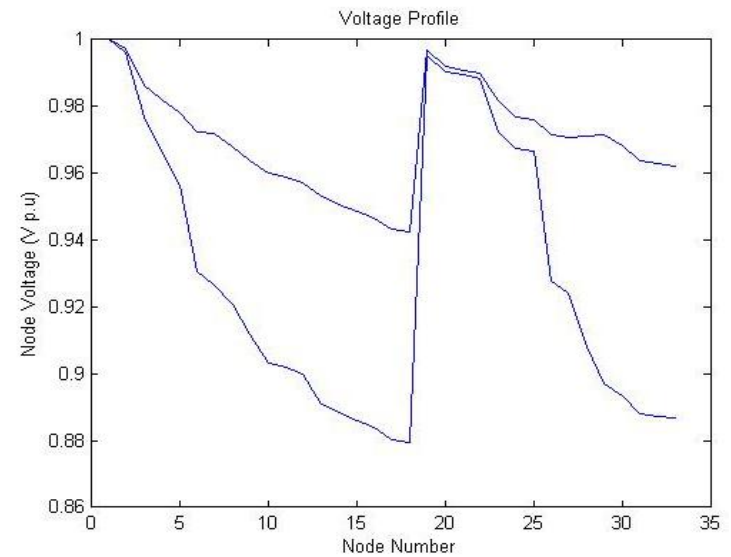

Fig3: Voltage profile without and with capacitor placement and PSO algorithm



Fig4: Voltage profile without and with capacitor-DG placement and PSO algorithm

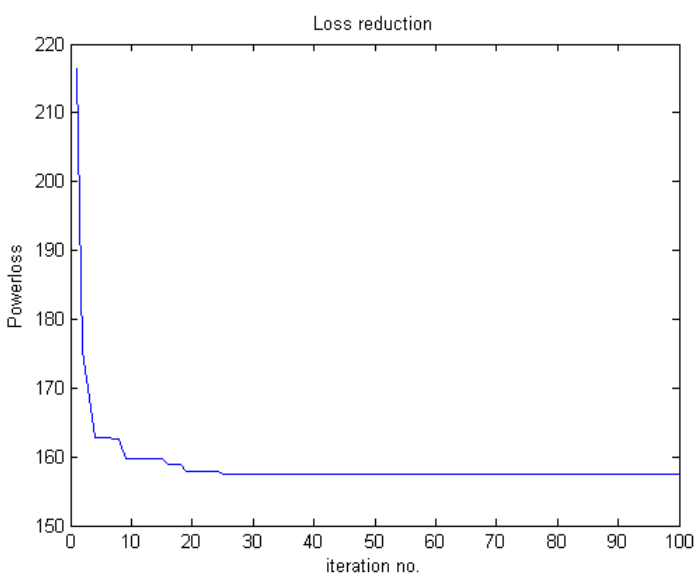

Fig5: Power Loss reduction using capacitor
From above results, we can say that the losses are reduced from 220 to $159.78 \mathrm{KVAR}$ I.e., nearly $27.68 \%$ by placement and sizing of capacitor in radial distribution system and using DG, losses obtained is $101.11 \mathrm{KW}$. This means that the proposed algorithm reduces losses to $45.67 \%$ by using DG in radial distribution system. The comparison was shown in table7.

The overall cost of the system reduces from $\$ 37,250$ to $\$ 26,843$ i.e., nearly $29.62 \%$ of the cost reduces. The net saving using capacitors is $10,407 \$$ year which is better than $8348 \$ /$ Year and by using DG the net saving is $11758 \$$ year. The result obtained says that, net saving improves from $24.66 \%$ to $40.84 \%$ of the system.

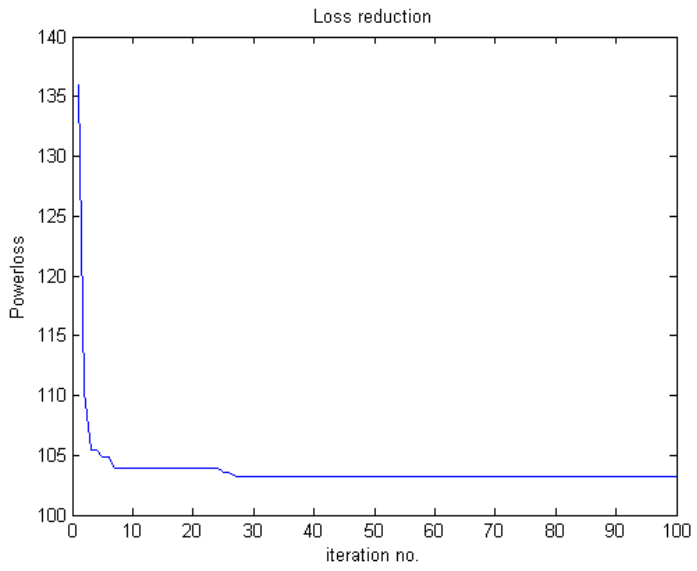

Fig6: Loss reduction using DG

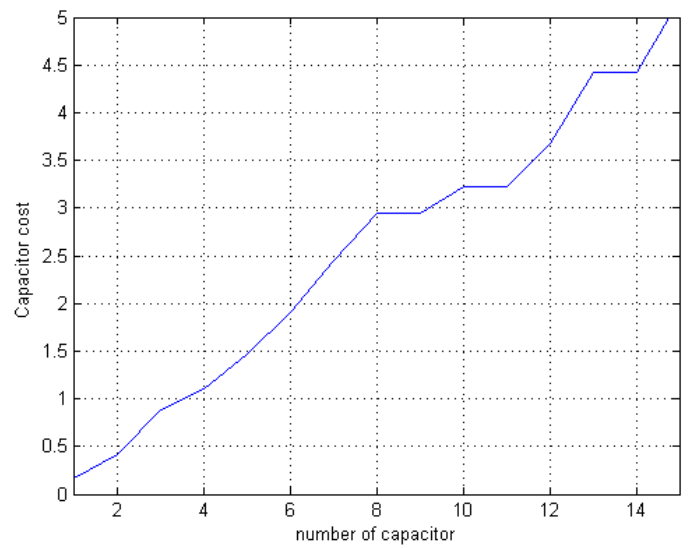

Fig8: cost of capacitors




Table 3: Loss sensitivity factors placed in descending order of a 33-bus radial distribution system

\begin{tabular}{|c|c|c|c|c|c|c|}
\hline ORDER & $\frac{\partial P_{\text {loss }}}{\partial Q}$ & Start Bus (p) & End Bus (q) & $V_{p}$ & $V_{q}$ & Norm[i] $=V_{q}(\mathrm{i}) / 0.95$ \\
\hline 1 & 0.0073 & 3 & 4 & 0.9829 & 0.9870 & 1.0389 \\
\hline 2 & 0.0063 & 4 & 5 & 0.9754 & 0.9825 & 1.0342 \\
\hline 3 & 0.006 & 5 & 6 & 0.9680 & 0.9781 & 1.0296 \\
\hline 4 & 0.0057 & 1 & 2 & 1.0000 & 1.0000 & 1.0526 \\
\hline 5 & 0.0050 & 2 & 3 & 0.9970 & 0.9971 & 1.0495 \\
\hline 6 & 0.0048 & 6 & 17 & 0.9496 & 0.9673 & 1.0182 \\
\hline 7 & 0.0046 & 18 & 19 & 0.9130 & 0.9475 & 0.9974 \\
\hline 8 & 0.0044 & 6 & 7 & 0.9496 & 0.9673 & 1.0182 \\
\hline 9 & 0.0040 & 17 & 18 & 0.9136 & 0.9485 & 0.9984 \\
\hline 10 & 0.0038 & 21 & 22 & 0.9922 & 0.9736 & 1.0248 \\
\hline 11 & 0.0037 & 19 & 20 & 0.9965 & 0.9951 & 1.0474 \\
\hline 12 & 0.0032 & 20 & 21 & 0.9929 & 0.9782 & 1.0297 \\
\hline 13 & 0.0032 & 22 & 23 & 0.9916 & 0.9701 & 1.0212 \\
\hline 14 & 0.0030 & 23 & 24 & 0.9793 & 0.9834 & 1.0352 \\
\hline 15 & 0.0028 & 8 & 9 & 0.9413 & 0.9626 & 1.0133 \\
\hline 16 & 0.0024 & 7 & 8 & 0.9462 & 0.9667 & 1.0175 \\
\hline 17 & 0.0014 & 24 & 25 & 0.9727 & 0.9768 & 1.0282 \\
\hline 18 & 0.0014 & 9 & 10 & 0.9350 & 0.9592 & 1.0097 \\
\hline 19 & 0.0006 & 25 & 26 & 0.9693 & 0.9735 & 1.0247 \\
\hline 20 & 0.0005 & 10 & 11 & 0.9292 & 0.9627 & 1.0134 \\
\hline 21 & 0.0004 & 7 & 28 & 0.9462 & 0.9667 & 1.0175 \\
\hline 22 & 0.0004 & 31 & 32 & 0.9178 & 0.9385 & 0.9879 \\
\hline 23 & 0.0004 & 10 & 31 & 0.9292 & 0.9627 & 1.0134 \\
\hline 24 & 0.0004 & 3 & 13 & 0.9829 & 0.9870 & 1.0389 \\
\hline 25 & 0.0003 & 13 & 14 & 0.9207 & 0.9605 & 1.0110 \\
\hline 26 & 0.0003 & 28 & 29 & 0.9337 & 0.9526 & 1.0028 \\
\hline 27 & 0.0002 & 32 & 33 & 0.9169 & 0.9378 & 0.9872 \\
\hline 28 & 0.0002 & 26 & 27 & 0.9477 & 0.9655 & 1.0163 \\
\hline 29 & 0.0002 & 11 & 12 & 0.9284 & 0.9628 & 1.0134 \\
\hline 30 & 0.0001 & 29 & 30 & 0.9255 & 0.9451 & 0.9949 \\
\hline 31 & 0.0001 & 14 & 15 & 0.9185 & 0.9597 & 0.9597 \\
\hline 32 & 0.0001 & 33 & 34 & 0.9166 & 0.9472 & 0.9970 \\
\hline 33 & 0.0000 & 15 & 16 & 0.9170 & 0.9532 & 1.0033 \\
\hline
\end{tabular}

Fig7: Optimization of power loss reduction

\begin{tabular}{|c|c|c|c|c|c|c|c|}
\hline \multirow{2}{*}{$\begin{array}{l}\text { No. of } \\
\text { units }\end{array}$} & \multirow[t]{2}{*}{ Type } & \multirow{2}{*}{\multicolumn{4}{|c|}{$\begin{array}{c}\text { Installation schedule for 33-Bus System } \\
\text { Size }\end{array}$}} & \multirow{3}{*}{$\begin{array}{l}\text { Losses } \\
163.93 \\
\end{array}$} & \multirow{3}{*}{$\begin{array}{c}\text { Loss } \\
\text { reduction } \% \\
25.48 \\
\end{array}$} \\
\hline & & & & & & & \\
\hline \multirow[t]{2}{*}{1} & Capacitor(KVAR) & 3600 & - & - & - & & \\
\hline & $\mathrm{DG}(\mathrm{KW})$ & 850 & - & - & - & 144.23 & 34.44 \\
\hline \multirow[t]{2}{*}{2} & Capacitor(KVAR) & 1500 & 2000 & - & - & 160.81 & 26.90 \\
\hline & $\mathrm{DG}(\mathrm{KW})$ & 850 & 950 & - & - & 101.11 & 37.12 \\
\hline \multirow[t]{2}{*}{3} & Capacitor(KVAR) & 1500 & 200 & 1800 & - & 158.82 & 27.80 \\
\hline & $\mathrm{DG}(\mathrm{KW})$ & 850 & 950 & 890 & - & 86.28 & 45.67 \\
\hline \multirow[t]{2}{*}{4} & Capacitor(KVAR) & 1200 & 200 & 1800 & 500 & 157.87 & 28.24 \\
\hline & $\mathrm{DG}(\mathrm{KW})$ & 850 & 950 & 890 & 0 & 86.28 & 45.67 \\
\hline
\end{tabular}

Table7: comparison between Capacitor and DG

\section{CONCLUSION}

In this paper, the problem of optimal placement and sizing of capacitor and DG is solved. The PSO technique is used as the optimization tool, with its discrete version. Unlike the traditional methods, PSO is a population based search algorithm, i.e., PSO has implicit parallelism. This property ensures PSO to be less susceptible to being trapped in local minima. Moreover, it has been noticed that the solution quality of the proposed algorithm does not rely on the initial population. Starting anywhere in the search space, the algorithm converges to the optimal solution.

The proposed algorithm has been tested on IEEE 33-bus radial distribution system and it gives superior results compared to both capacitor and DG. Solving the optimal placement and sizing of capacitor and DG problems gives the advantages of using capacitor and DGs, which improve the system power factor, improves the system voltage profile, reduce losses due to compensation of real and reactive components of power flow and reduces overall 
cost of the system per year. By decreasing the flow through cables, the system loads can be increased without adding any new cables or overloading the existing cables.

\section{REFERENCES}

[1] K. Prakash, M. Sydulu, Particle swarm optimization based capacitor placement on radial distribution systems, IEEE Power Eng. Soc. General Meet. (2007) (June).

[2] J.B.V.Subrahmanyam, Optimal capacitor placement in unbalanced radial distribution networks, J. Theor. Appl.Inform. Technol. 6 (1) (2009) 106-115.

[3] T.S. Chung, Ge Shaoyun, A recursive LP-based approach for optimal capacitor allocation with cost-benefit consideration, Electric Power Syst. Res. (1997) 129-136.

[4] S.Bouri, A.Zeblah, A.Ghoraf, S.Hadjeri, H.Hamdaoui, An Ant colony optimization to shunt capacitor allocation in radial distribution systems, Acta Electrotech. Inform. 5 (4) (2005).

[5] Samir Azim, K.S.Swarup, Optimal Capacitor Allocation in Radial Distribution Systems under APDRP, IEEE Indicon 2005 Conference, Chennai, India.

[6] Tamer Mohamed Khalil, Hosam K.M. Youssef, M.M.Abdel Aziz, A binary particle swarm optimization for optimal placement and sizing of capacitor banks in radial distribution feeders with distorted substation voltages, in: AIML 06 International Conference, Sharm El Sheikh, Egypt, 13-15 June 2006

[7] D. Das, P.Kothari, A.Kalam, Simple and efficient method for load flow solution of radial distribution networks, Electr. Power Energy Syst. 17 (5) (1995) 335-346.

[8] M.Chis, M.M.A.Salama, S.Jayaram, Capacitor placement in distribution systems using heuristic search strategies, IEE ProcGener. Trunsm. Distrib. 144 (3) (1997).

[9] S.Ghosh, S.P.Ghoshal and S.Ghosh, "Optimal sizing and placement of DG in network", International Journal of Electrical Power and Energy Systems. 2010, 32(8): 849-856.

[10] K.Varesi, "Optimal Allocation Of DG units for Power Loss Reduction and Voltage profile Improvement of Distribution networks using PSO Algorithm," World Academy of Science, Engineering and Technology 602011. 